\title{
A Casa de Parto David Capistrano Filho pelas lentes de uma fotógrafa
}

\author{
David Capistrano Filho Birthing House \\ through the lenses of a photographer
}

\section{Adriana Medeiros}

Fotógrafa, Instituto Nacional de Saúde da Mulher, da Criança e do Adolescente Fernandes Figueira/ Fiocruz.

Rio de Janeiro - RJ - Brasil amedeirinhos@gmail.com

Recebido em 27 jan. 2018. Aprovado em 2 jul. 2018.
MEDEIROS, Adriana. A Casa de Parto David Capistrano Filho pelas lentes de uma fotógrafa. História, Ciências, Saúde - Manguinhos, Rio de Janeiro, v.25, n.4, out.-dez. 2018, p.1171-1183.

\section{Resumo}

Esse artigo é resultado do acompanhamento fotodocumental à Casa de Parto David Capistrano Filho por 12 anos descontinuados (entre 2005 e 2017). As fotos narram o cotidiano da casa, documentando suas atividades regulares com as famílias, os momentos festivos, domésticos, terapêuticos, comunitários e de exercício de cidadania pelo direito à saúde reprodutiva de qualidade e autônoma. A Casa de Parto é um equipamento público de saúde que atende a gestantes de baixo risco habitual em Realengo, zona oeste do Rio de Janeiro. Sua proposta mais ampla de saúde se baseia em educação e informação por meio do acolhimento de proximidade e vínculo, práticas não medicalizadas e cuidado transdisciplinar.

Palavras-chave: parto humanizado; enfermagem obstétrica; casas de parto; saúde da mulher; cuidado.

\begin{abstract}
This article is the outcome of a project to photographically document the David Capistrano Filho Birthing House (Casa de Parto David Capistrano Filho) continuously for 12 years from 2005 to 2017. The photographs narrate daily life in the institution: its regular activities with families, celebrations, its domestic, therapeutic, and community activities, and activities involving the exercise of citizenship for the right to autonomy and quality in reproductive health care. The birthing house is a public health institution that serves women with lowrisk pregnancies in Realengo, a district in the west zone of Rio de Janeiro. More broadly, it proposes to educate and inform by creating bonds and relationships of proximity and by fostering non-medical practices and transdisciplinary care.
\end{abstract}

Keywords: humanized childbirth; obstetric nursing; birthing houses; women's health; care. 
$\mathrm{M}$ anhã de sábado de frio e chuva. Chegando à estação de Realengo (na zona oeste do Rio de Janeiro), procuro um moto táxi para me levar à Casa de Parto David Capistrano Filho (CPDCF). Como não lembrava o nome da rua, perguntei ao condutor se conhecia: "Sei, na rua do valão? Meu filho nasceu lá! Parto vertical, nunca vi! Minha mulher teve filho em pé, foi "parto-rapel'!" Todos riram. Ao chegar, não havia mais chuva nem frio: em frente à casa, várias pessoas suavam a camisa pintando a grade, plantando mudas de toda a sorte! Era um mutirão pela reforma da casa, organizado pela recémfundada Associação de Apoio à Casa de Parto David Capistrano Filho (ReParto). Enquanto isso, no interior de uma suíte aguardava-se a chegada do bebê de número três mil. Todos trabalhavam de alguma forma pelo nascimento.

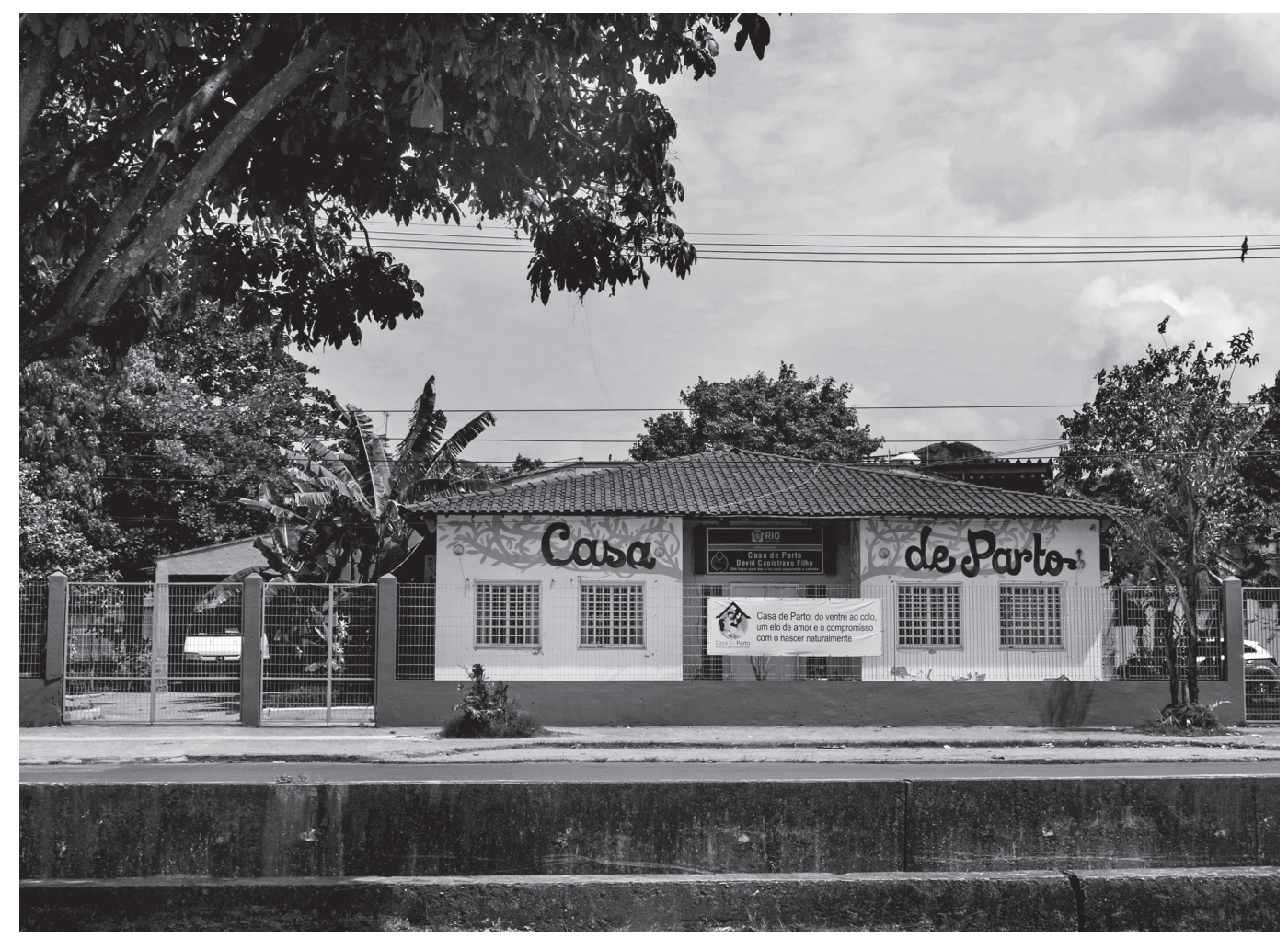

Imagem 1: Vista frontal da Casa de Parto David Capistrano Filho (CPDCF) (Foto de Adriana Medeiros, 2017).

A casa é pequena e simples, branca e rosa, numa rua de pouco movimento em frente a um valão - canal de escoamento de águas contaminadas -, com chuva e esgoto a céu aberto.

A cena é verdadeiramente bucólica e silenciosa. Essa paz recôndita, vista por quem chega, mantém-se mesmo com muitas atividades no local. Foi assim no dia do mutirão. Um pequeno trator espalhava terra nos jardins, enquanto funcionários, apoiadores e famílias plantavam mudas ou pintavam as grades que cercam a casa. Quem chegava trazia um bolinho. A aparência de lar associada a rotinas domésticas - visita com bolo, 
cuidados com as plantas, pintura da casa em mutirão - evoca uma sensação aprazível de proximidade e acolhimento, considerados porta de entrada para um atendimento de qualidade. Como essas características não são muito convencionais em unidades de saúde, tive curiosidade em saber mais sobre a chegada das mulheres assistidas na casa. Perguntei sobre isso à Leila por duas vezes. Na primeira vez, em 2005, a casa de parto era pouco conhecida, e sua proposta de acompanhamento era muito nova para os parâmetros de atendimento hospitalar (Moura, 2009). No entanto, a casa trazia segurança e confiança às usuárias. Perguntei o que atraía e mantinha as mulheres no programa da casa. Na ocasião, o atrativo era justamente o acesso. Na época, com a rede de saúde desarticulada, as mulheres perambulavam de hospital em hospital em busca de vaga e chegavam nas maternidades sem acompanhamento pré-natal, já em trabalho de parto. A qualidade de acesso dependia de ter um lugar de referência para parir. E isso a CPDCF garantia. Quando repeti a pergunta em 2017: o que mais atraía as mulheres à CPDCF? A diretora respondeu: "O acesso à casa é livre!", agora se referindo ao convívio e à livre utilização da casa pelas usuárias. Superada a dificuldade de referência no atendimento, o acesso também significava apropriação do espaço público pela comunidade.

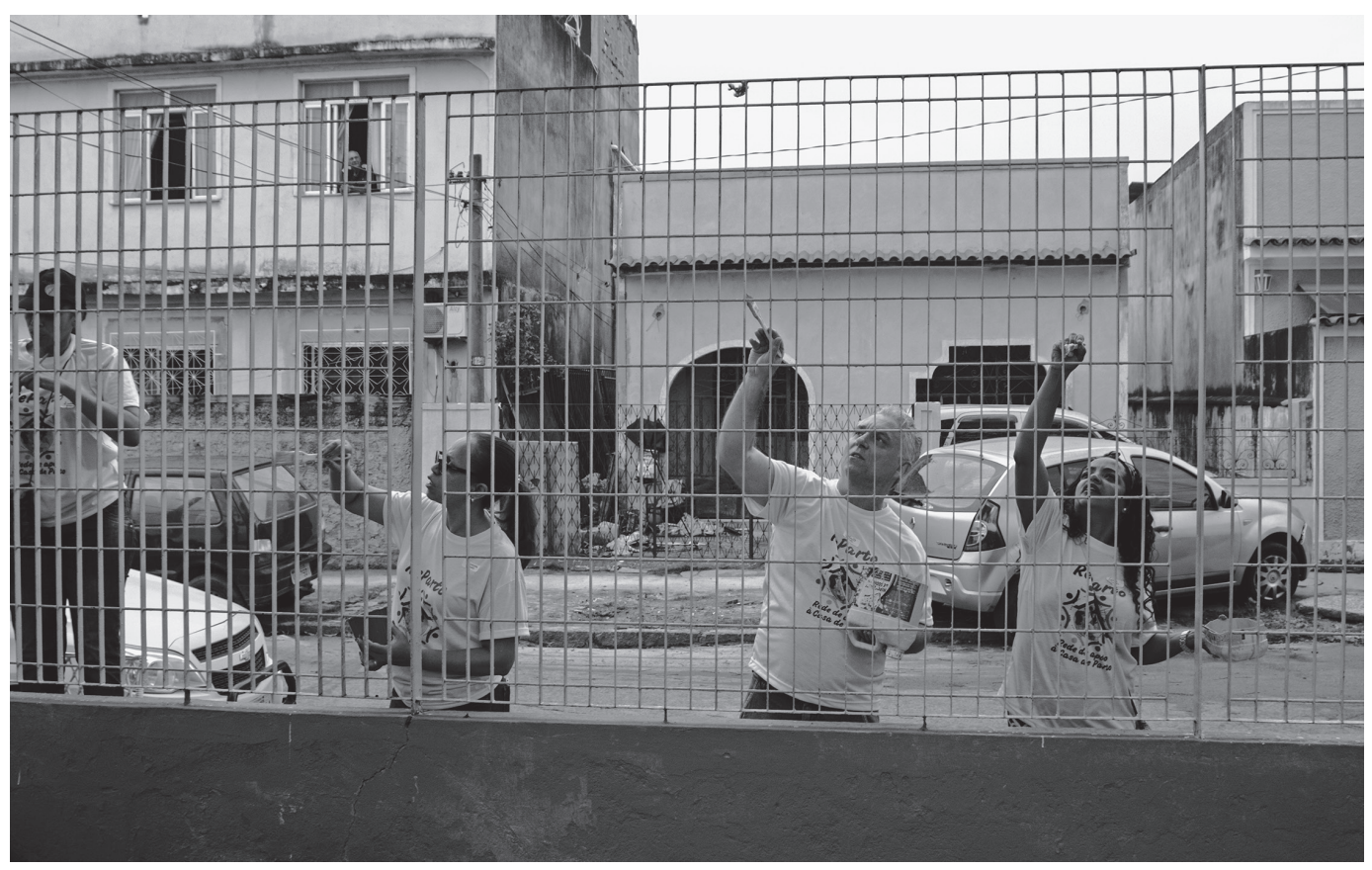

Imagem 2: Apoiadores da CPDCF em mutirão pela reforma da casa (Foto de Adriana Medeiros, 2017).

A Casa de Parto David Capistrano Filho é um equipamento público do município do Rio de Janeiro, integrada ao Sistema Único de Saúde (SUS) e de modelo comunitário, ou seja, a estrutura física da casa é independente da estrutura de um hospital. A equipe está capacitada para atender gestantes de baixo risco. Os riscos habituais são monitorados por meio das agendas de consultas, exames e da participação nas atividades educativas, incorporadas ao 
pré-natal como parte do acompanhamento. Casos de intercorrência são conduzidos a um hospital próximo de referência (a 15 minutos de distância) por uma ambulância 24horas estacionada à disposição (CPDCF, s.d.).

O porte da casa é pequeno se comparado às maternidades brasileiras: realiza cerca de trezentos partos por ano, contra quatrocentos a seiscentos partos ao mês nas maternidades. Tanto o tamanho do equipamento quanto o ritmo de atendimentos atendem a uma lógica e a uma estratégia de enfrentamento às altas taxas de mortalidade materna e cesarianas desnecessárias. O atendimento é mais personalizado, com ênfase no cuidado, na informação e na educação. É administrada exclusivamente por enfermeiras obstétricas que atuam ou atuaram em maternidades, inclusive de alto risco (Romar, 2014).

A estrutura da casa tem uma disposição circular, comunicando todos os setores: a recepção, as três suítes para acolher as famílias em trabalho de parto, a administração, a sala de grupo e duas salas de consultas. A cor rosa-choque predomina em todos os ambientes, e neles a presença de objetos "familiares" é forte, utilizados seja na decoração, seja na divulgação das atividades realizadas na própria casinha, apelido da CPDCF. Nas paredes são fixadas fotos de bebês e suas famílias, cartas de mães e pais e colagens em cartazes desenvolvidos em atividades educativas. Logo criamos uma identificação visual e imaginária com a casa e suas usuárias. O espaço está sempre se renovando, por ser utilizado como recurso de acesso e comunicação.

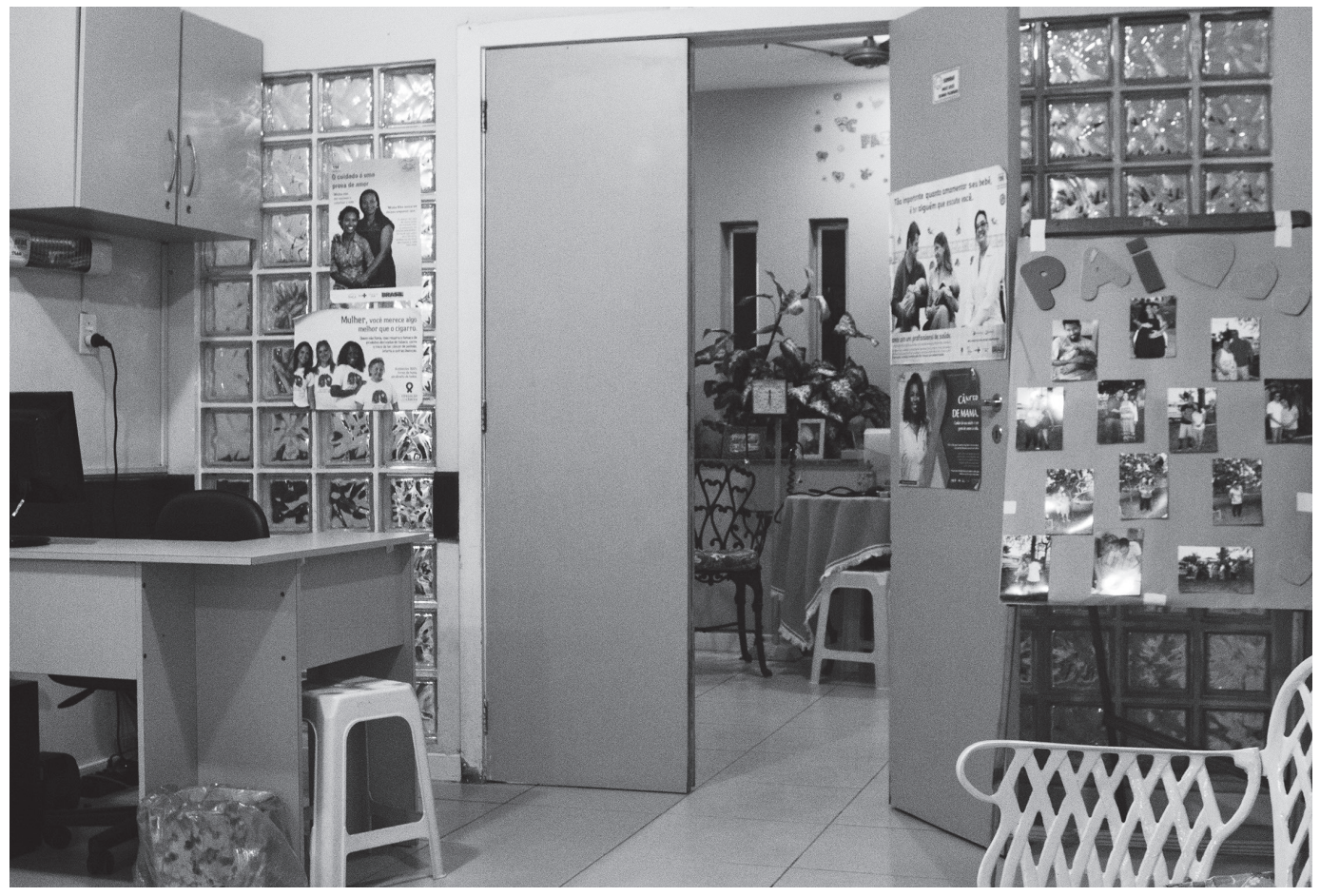

Imagem 3: Vista da recepção

(Foto de Adriana Medeiros, 2017). 
Conheci a CPDCF em um de seus aniversários, em um 8 de março, há 12 anos. Essa comemoração é uma atividade aberta, momento de encontro entre equipe, comunidade, parceiras e parceiros. Os aniversários e outras festas (chá de bebês, por exemplo), o colorido da casa e dos uniformes e o cheiro de feijão sempre estiveram presentes em minhas lembranças da casinha. Desde então, estive com a equipe da casa e com suas "mães" em variados momentos: uns de alegria e celebração e outros de tensão e luta. Sua prática desmedicalizada, sobretudo sem supervisão médica, provocou muitas discussões, críticas e, inclusive, a interrupção de suas atividades por duas vezes. Uma em 2009, fechando a casa por 23 dias por não adequação aos protocolos hospitalares, e outra em 2017, restringindo seu trabalho a consultas sem solicitação de exames (a ação ainda está em andamento).

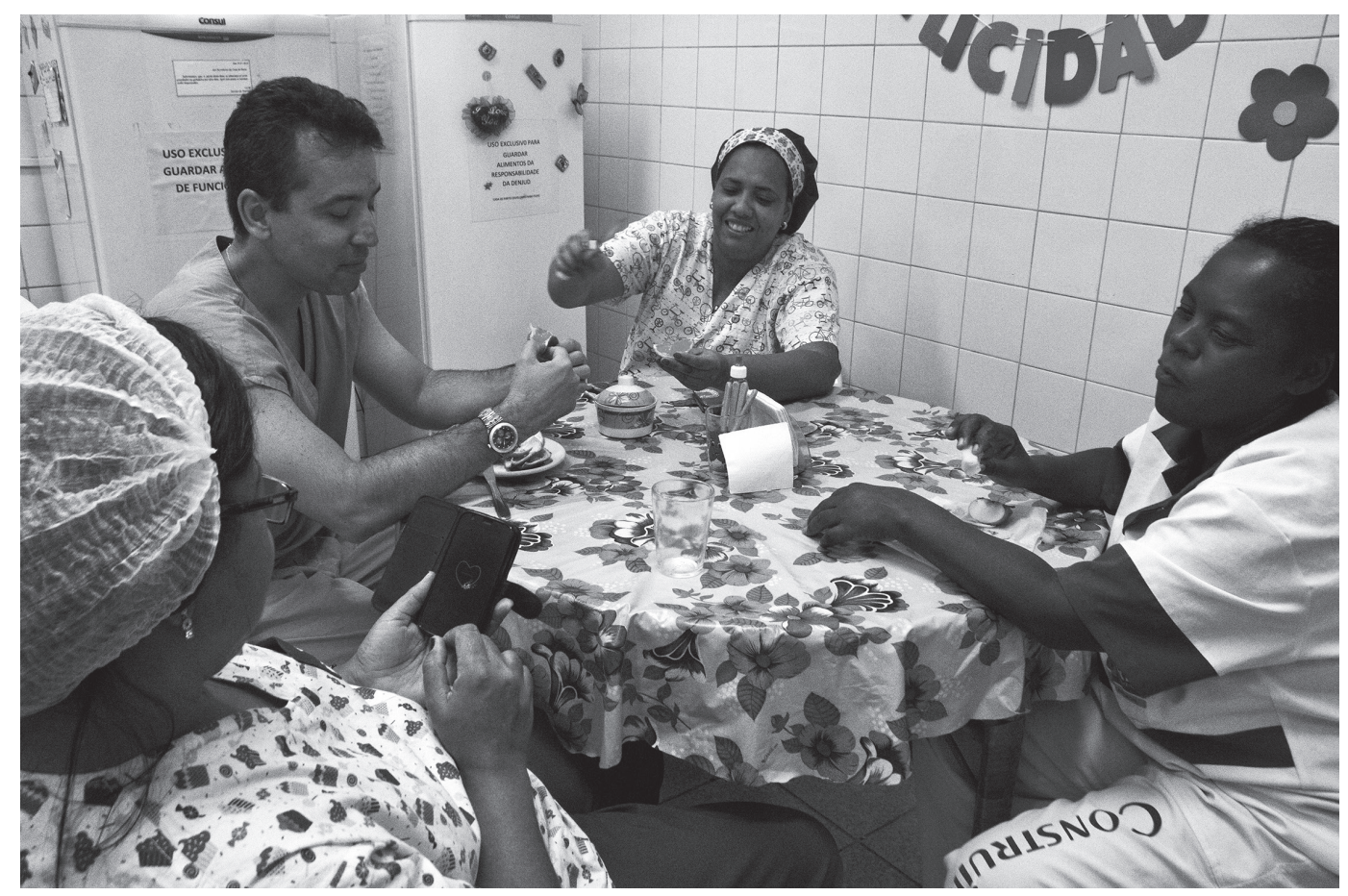

Imagem 4: Cozinha da casa: funcionários da CPDCF (de saúde e de limpeza) tomando café juntos (Foto de Adriana Medeiros, 2014).

No acolhimento, acorda-se com as famílias a responsabilidade de participação nas atividades educativas do programa de acompanhamento. As oficinas são variadas, tratam de direitos, de cuidado, da relação com o corpo e com a família. Explicam a fisiologia do parto e também informam tudo que se refere à saúde para a vida toda da mulher e da família; desconstroem mitos e tabus sobre sexualidade, gestação, parto e pós-parto. A ideia é atingir toda a rede de afeto e cuidado ligada à mulher. Seja avó, seja companheiro(a), vizinho(a), amigo(a) (Romar, 2014). 


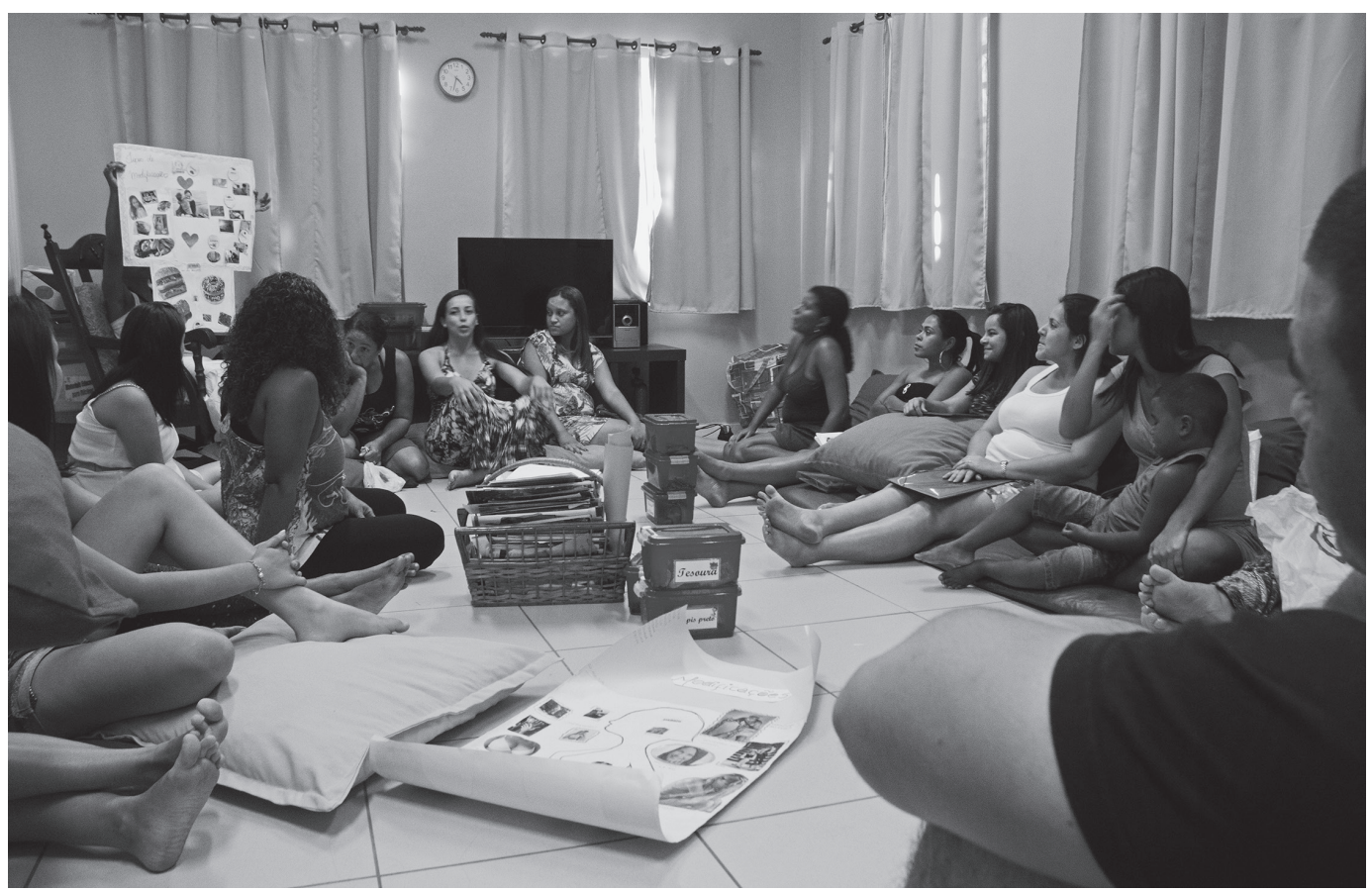

Imagem 5: Atividade educativa e consulta coletiva com as gestantes e familiares no pré-natal (Foto de Adriana Medeiros, 2014).

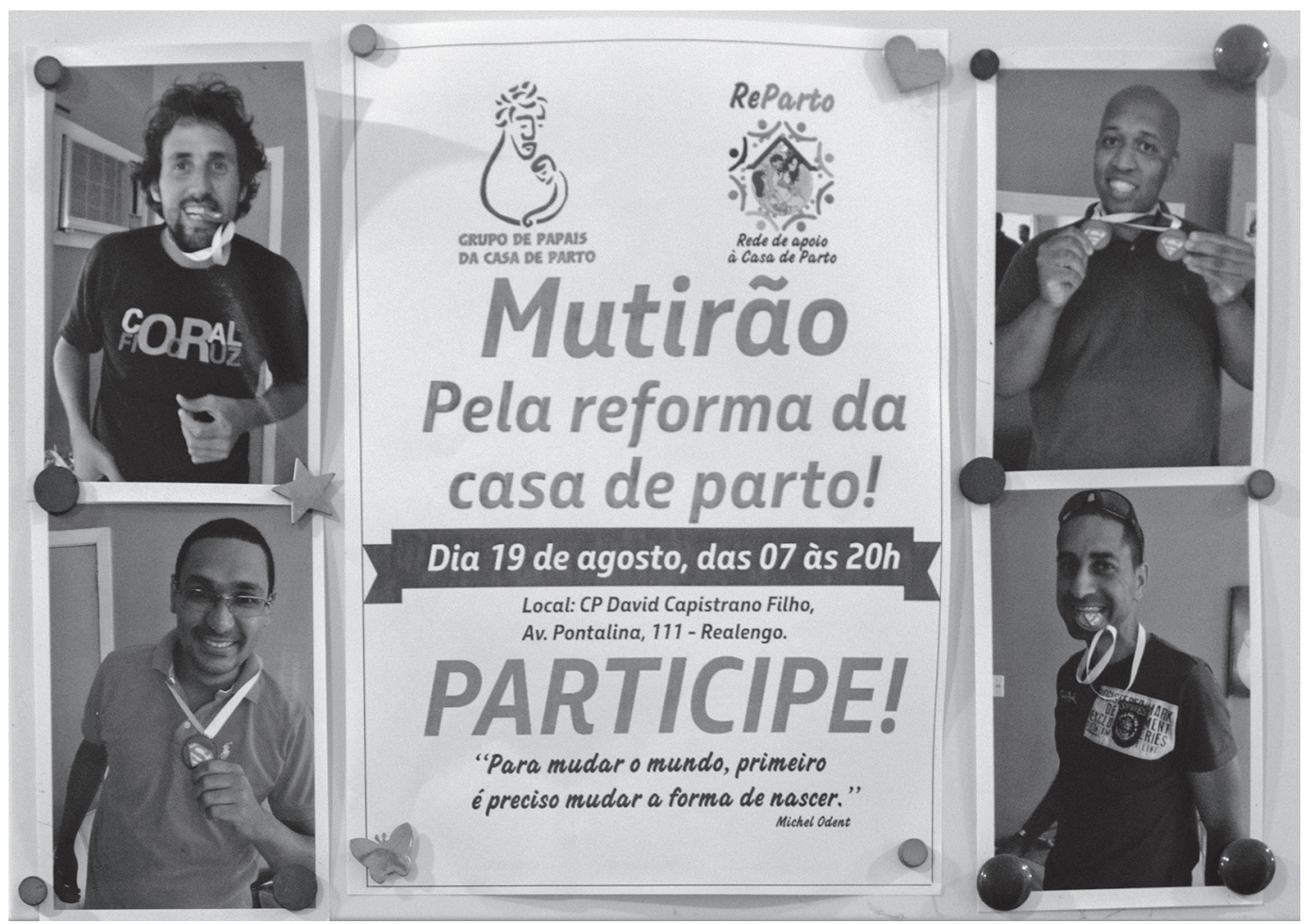

Imagem 6: Convocatória do mutirão para o grupo de pais

(Foto de Adriana Medeiros, 2017). 
Os pais se reúnem na casa para conversar sobre paternagem. Teo Cordeiro, um dos pais, teve uma experiência plena com o nascimento de seus dois filhos (Camilo e Havana), até que se tornou o principal cuidador. Sentia falta de um espaço só para os homens: "Nós não temos um espaço para falar do que é ser pai entre nós, das dificuldades, das dúvidas. Ali nós contamos sobre a nossa experiência, não nos acusamos e nada do que é falado sai da sala". A participação paterna é cada dia maior, mesmo não havendo compromisso de união, o pai está presente em todo o processo de preparação e informação.

Para a manutenção de vínculo, confiança e co-responsabilidade, todas as partes envolvidas no processo de parto assumem compromissos: a gestante, conhecendo e apropriando-se de sua expressão, saúde e processo; o pai, com participação e acolhimento; e o profissional de saúde, confiando na potência do corpo da mulher e do bebê para parir e nascer. "O objetivo é o que importa, não os papéis fixos!”, afirma a enfermeira obstétrica Edymara Medina, confiante no empoderamento feminino e nas práticas não convencionais: "As práticas não convencionais são o resultado da desconstrução da prática ... seja desenvolver o trabalho com a mãe, com a avó, com o pai ou quem estiver no círculo de afeto e confiança".

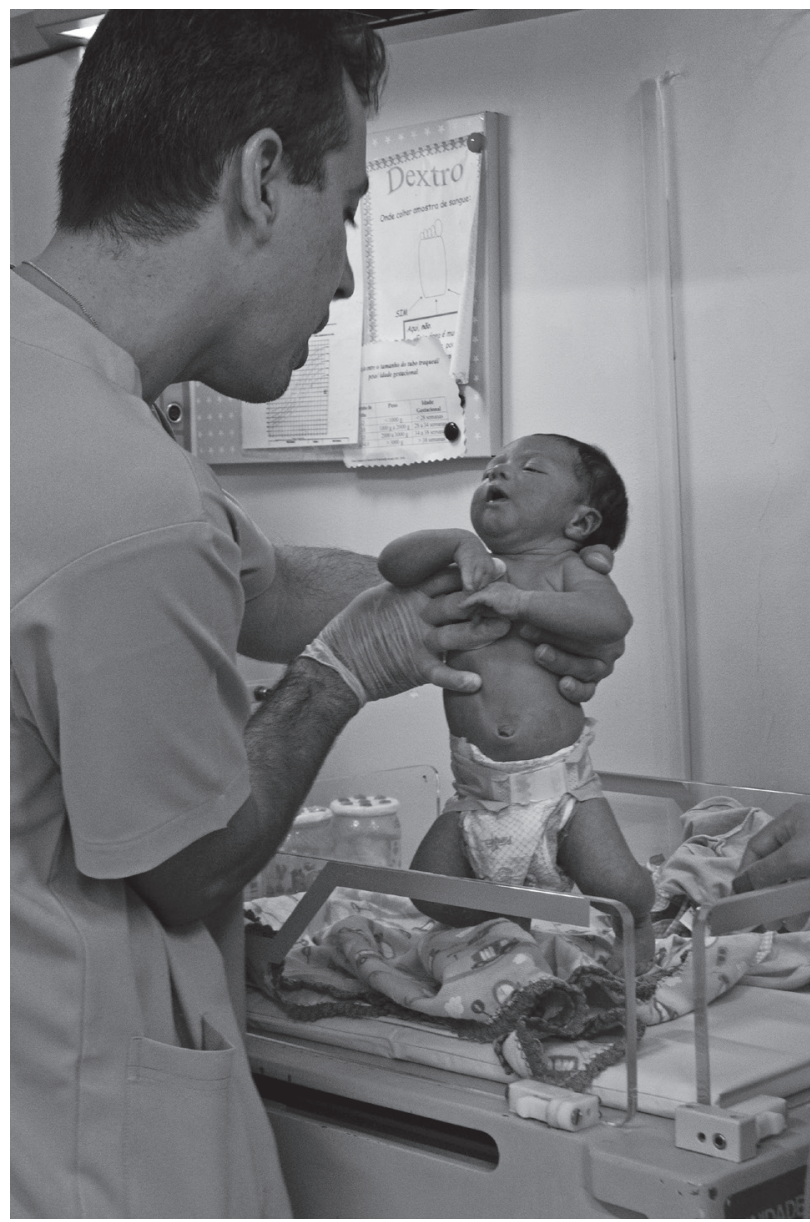

Imagem 7: Enfermeiro obstétrico em consulta (Foto de Adriana Medeiros, 2014). 


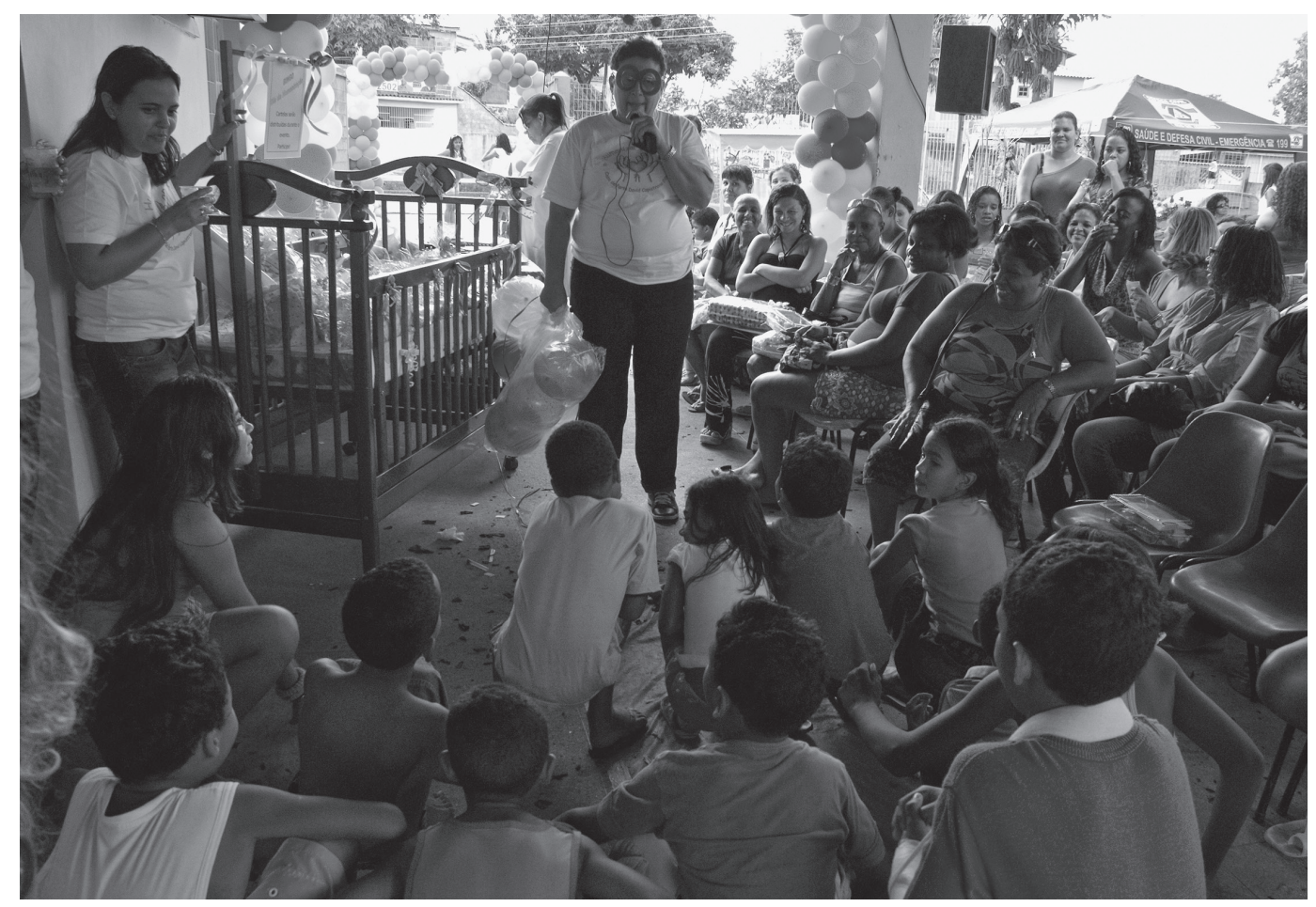

Imagem 8: Atividade lúdica de enfermeiras com crianças (Foto de Adriana Medeiros, 2012).

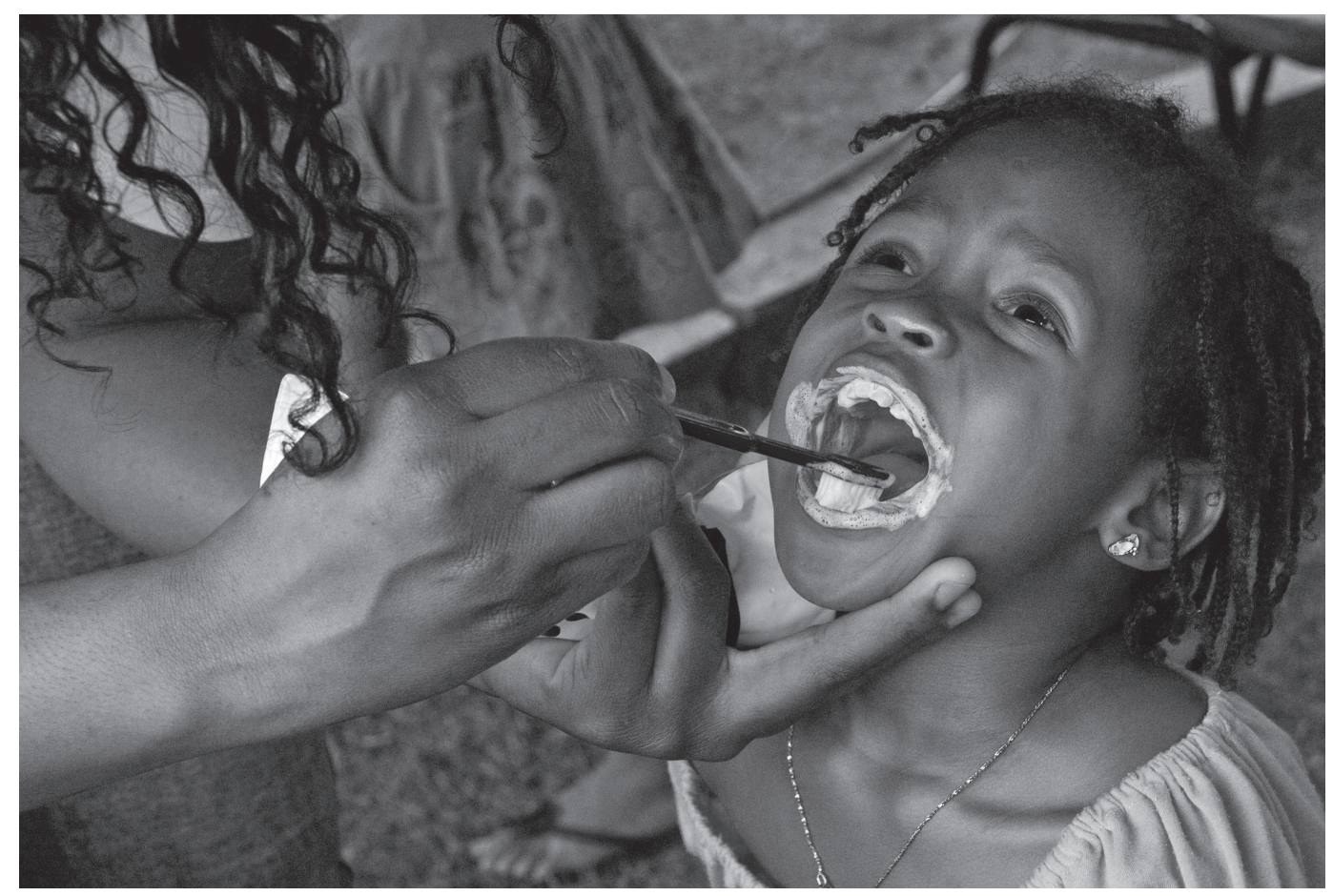

Imagem 9: Parceria com a Faculdade de Odontologia (Foto de Adriana Medeiros, 2012). 
O trabalho de parto e o parto acontecem na suíte com bem pouca luz e muita liberdade (de expressão, movimento e acompanhamento de escolha da parturiente). O plano de parto escolhido pela mulher define o ritual.

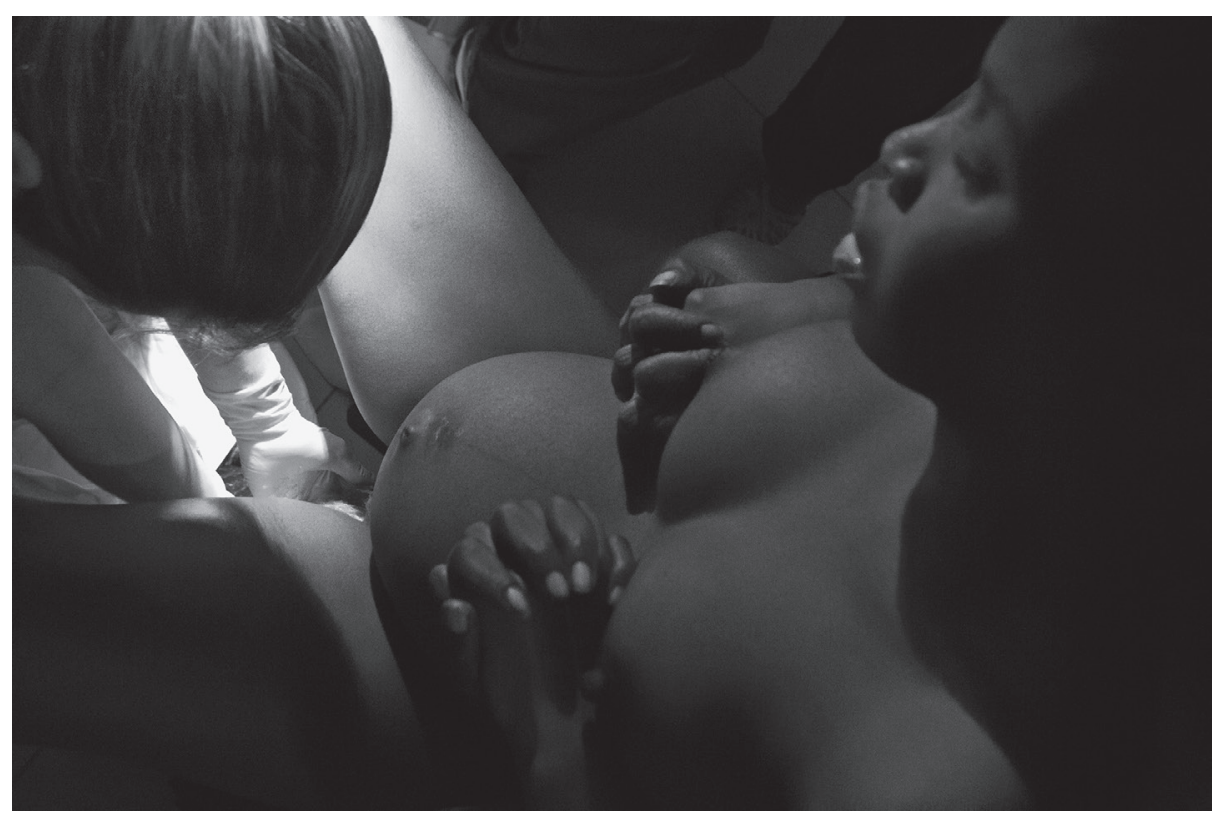

Imagem10: Nascimento numa suíte da CPDCF (Foto de Adriana Medeiros, 2014).

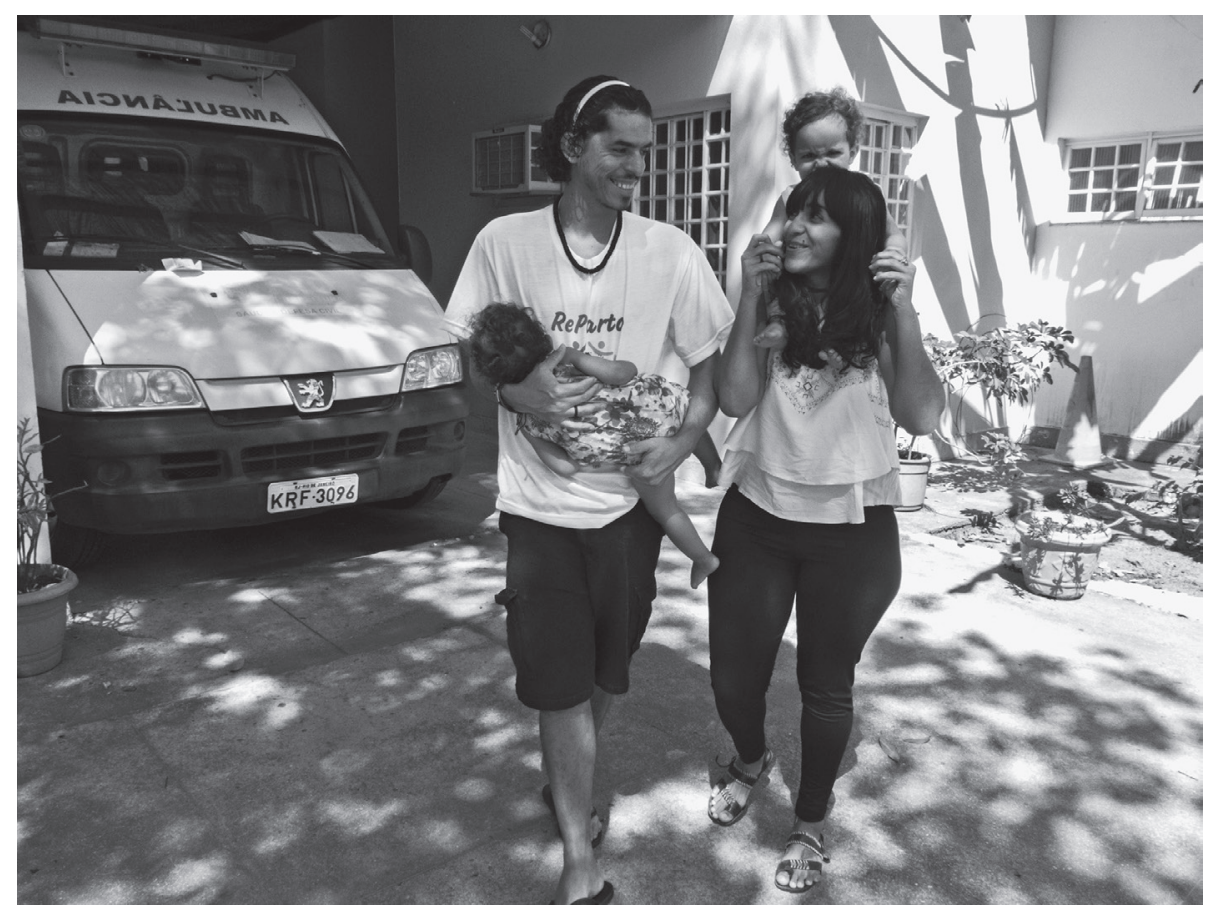

Imagem 11: Família assistida na casa de parto, Danielle Ramos e Rêneo Augusto (Foto de Adriana Medeiros, 2017). 
São muitas as histórias dos processos de parto. Para cada mulher e de cada filho também. Conheci Danielle Ramos no dia seguinte ao seu parto. Pariu duas vezes lá: na primeira vez, teve medo de ser transferida - além de ter se apaixonado pela equipe da casa de parto desde o primeiro contato, no acolhimento, presenciara uma experiência anterior negativa na maternidade de referência quando acompanhou sua própria mãe. Esse medo de ser transferida foi expresso nas oficinas e em longas conversas nas consultas. O trabalho de parto foi muito longo: trinta horas. Assim que soube que estava tudo bem e que seu bebê nasceria lá, nasceu. Saber sobre o seu medo a ajudou a parir: "Acho que o diferencial do cuidado humanizado daqui é muito isso: te explica o que vai acontecer, como é... então não te prepara só para o parto. É para lidar com a situação como um todo". Já seu segundo parto transcorreu com tranquilidade e muito rápido: sequer chegou até a suíte.

A história da CPDCF foi sendo construída e idealizada ao longo de uma trajetória que articulou o movimento feminista ao movimento sanitarista. O Ministério da Saúde ter garantido às enfermeiras obstétricas o campo obstétrico (pré-natal, parto e pós-parto) de maternidades localizadas em áreas populosas foi um importante passo. Foi decisiva a experiência na antiga maternidade Leila Diniz, na Zona Oeste do Rio de Janeiro área de condições sanitárias precárias e população social e economicamente periférica. Representou um laboratório de ações e práticas que reuniu uma equipe comprometida com a humanização no parto e que atualmente corresponde à maioria das enfermeiras obstétricas da casa de parto de Realengo, incluindo sua diretora, Leila de Azevedo, ex-chefe de enfermagem na referida maternidade Leila Diniz, onde sua experiência se deu tanto com atendimento a partos de baixo risco como de alto risco (Moura, 2009).

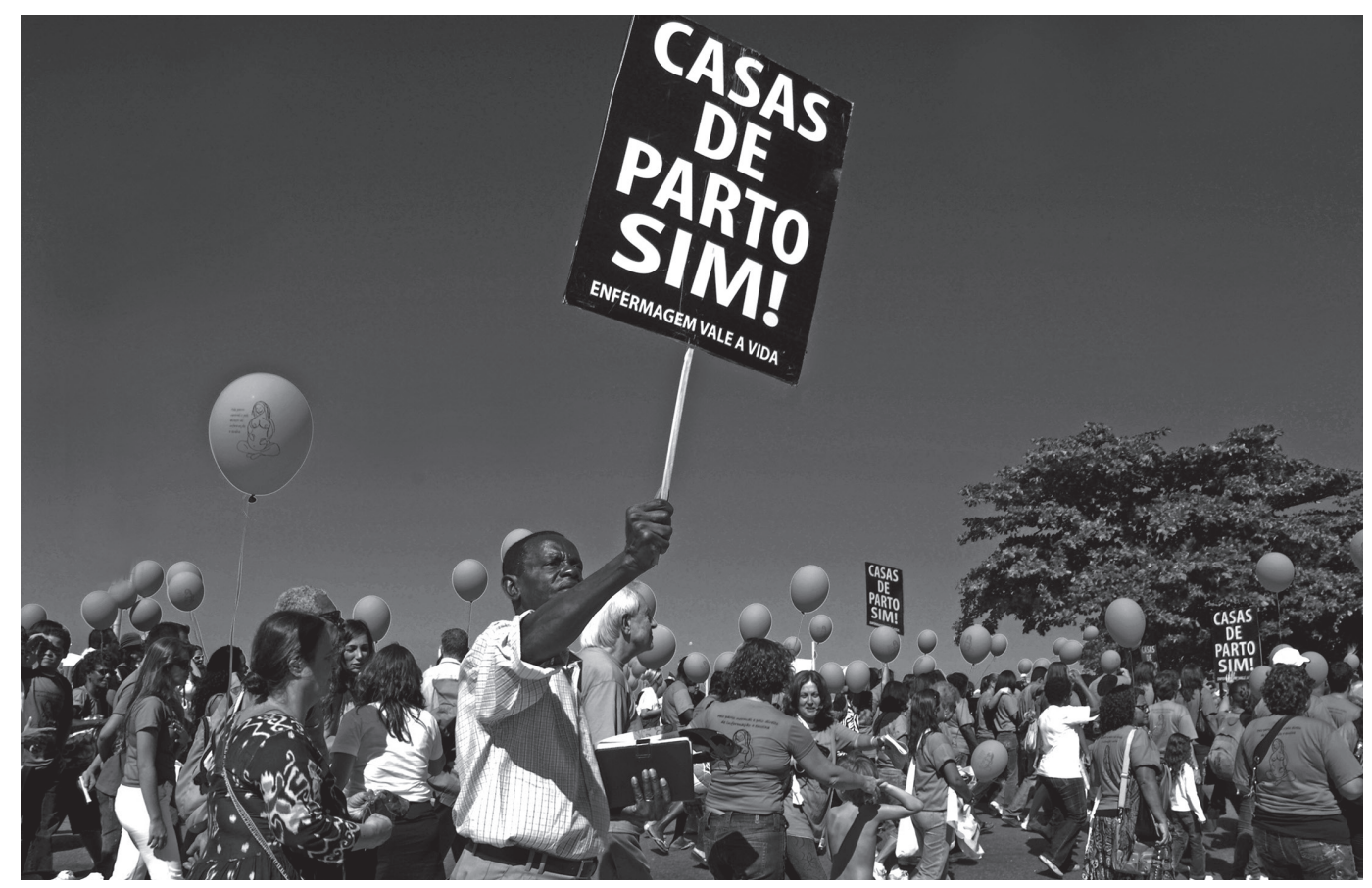

Imagem 12: Marcha pelo Parto Humanizado, organizado por várias entidades em protesto pelo fechamento das casas de parto CPDCF e de Juiz de Fora, Copacabana (Foto de Adriana Medeiros, 2009). 


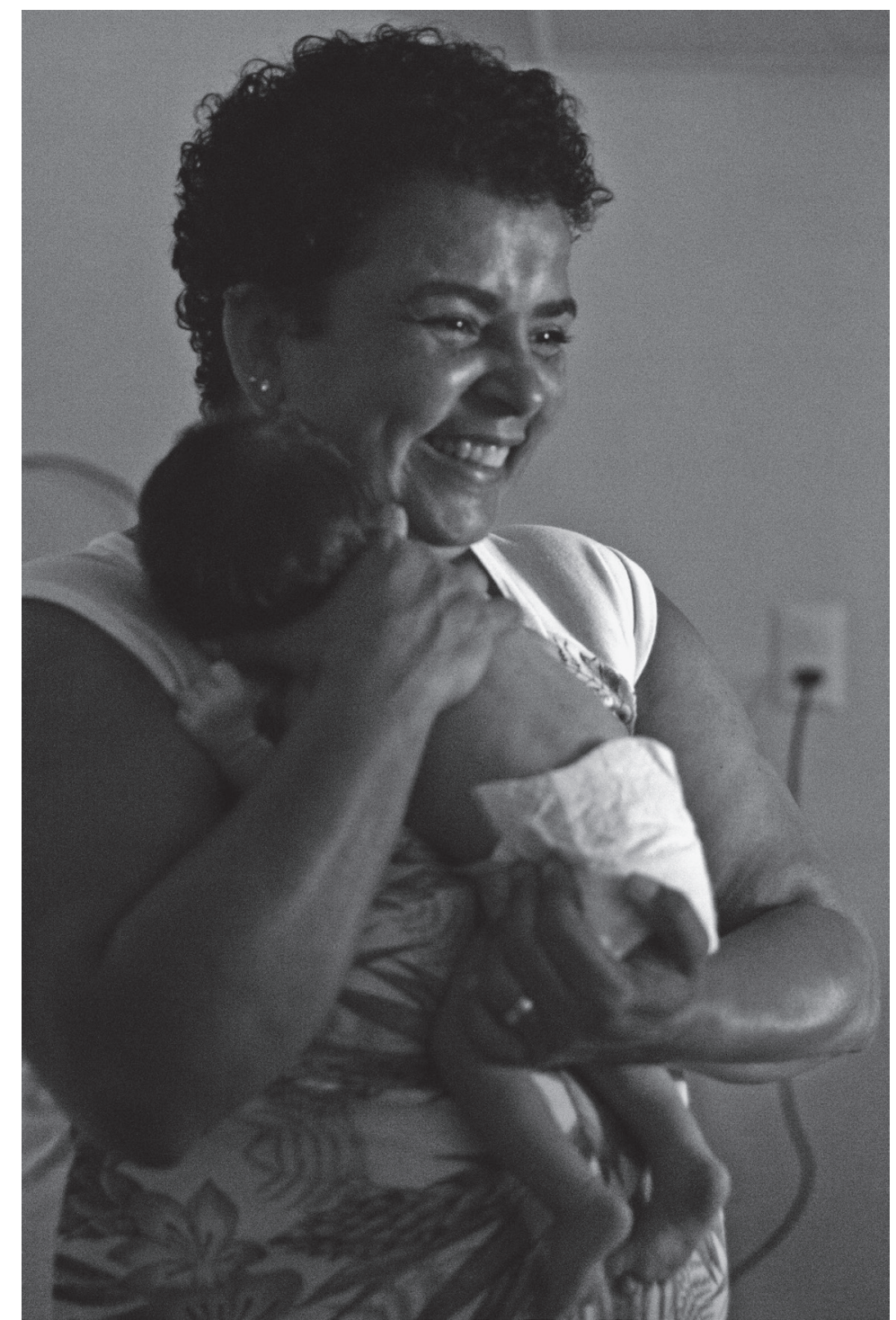

Imagem 13: Leila de Azevedo Gomes, enfermeira obstétrica e primeira diretora da CPDCF (Foto de Adriana Medeiros, 2014).

Atualmente, passados 13 anos e nenhum caso de mortalidade materna, a casa enfrenta novos desafios, relacionados à crise política e social do país. É preocupante a mudança nas características das usuárias: "De um ano para cá, a situação de risco habitual tem se alterado para alto risco. Com 34 semanas, as mulheres começam a desenvolver riscos. Tudo muito social", conclui Leila. Percebe-se uma piora nutricional, um aumento do estresse. O número de atendimentos também caiu abruptamente. Essas mudanças acontecem em um contexto de transição da gestão na casa e de um novo processo judicial que questiona a competência da enfermeira obstétrica para solicitar exames, comprometendo seu funcionamento autônomo. ${ }^{1}$ 


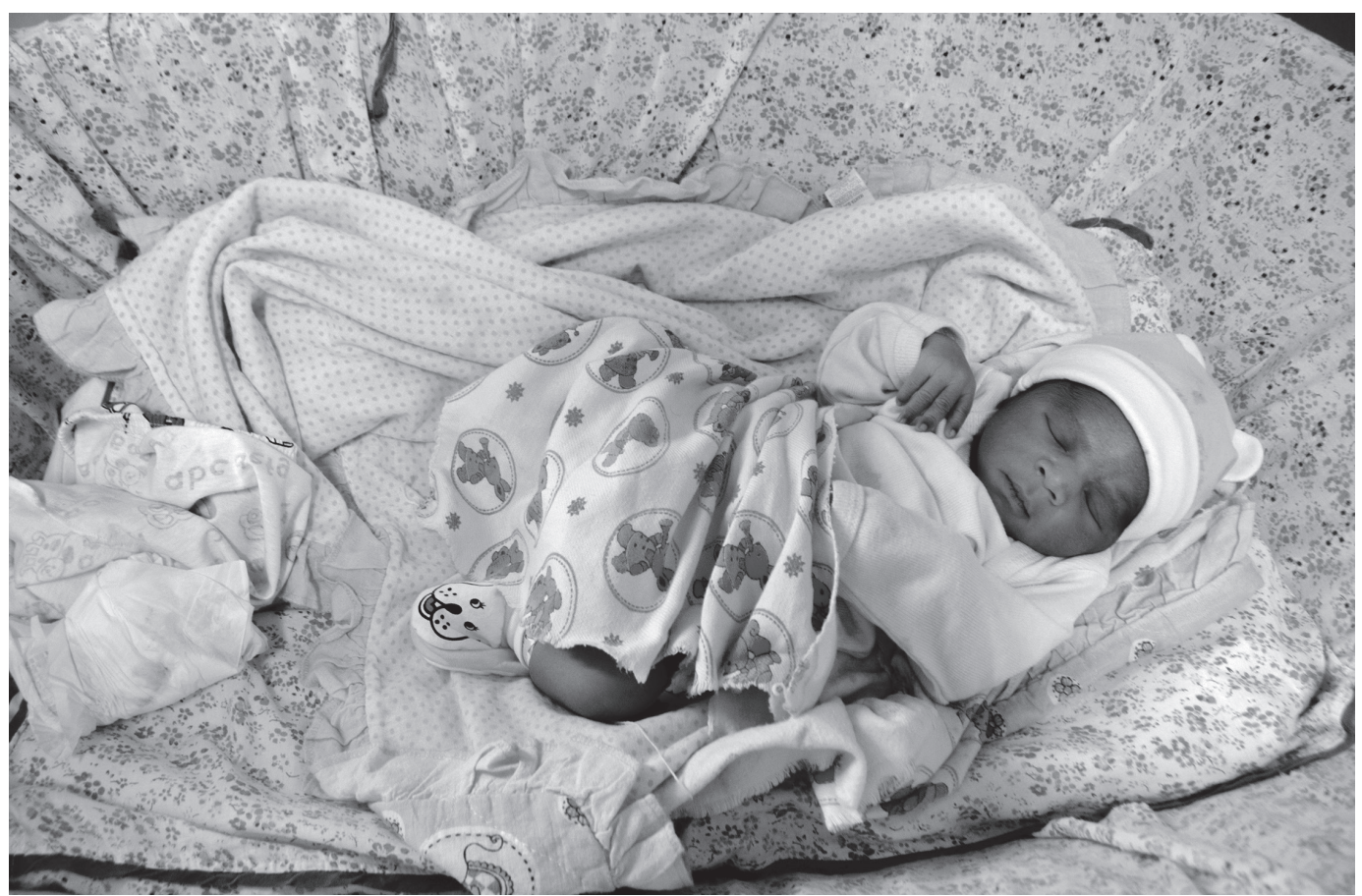

Imagem 14: Bebê nascido na CPDCF (Foto de Adriana Medeiros, 2014).

\section{Considerações finais}

A Casa de Parto David Capistrano Filho faz pensar nas relações possíveis entre poderes públicos e poder comunitário. Usuárias e profissionais de saúde alternam-se em uma luta pela liberdade de acesso e pela autonomia: luta democratizante, sempre em risco. A satisfação e o vínculo entre usuárias, funcionárias e enfermeiras podem ser vistos como qualidade de atendimento e acesso à saúde. A valorização do cuidado, a familiaridade do ambiente (quase doméstico), a comunicação presente e exercida em todo o seu potencial (no espaço, nas atividades, nas festas e nas consultas) promovem cuidado de forma muito ampla. Podem-se identificar os resultados dessas atividades nas mensagens, desenhos e fotos espalhados pelas paredes da casa. Essa acolhedora forma de vivenciar o parto e o nascimento é percebida até nas crianças, que brincam livremente nesse ambiente enquanto seus irmãos ou irmãs nascem. Nos limites de suas possibilidades, essa experiência é uma contribuição a um serviço de saúde de qualidade, um direito reprodutivo e social.

\section{NOTA}

\footnotetext{
${ }^{1}$ A competência do exercício profissional da enfermeira obstétrica, regulamentada por lei a partir de 1996 e reconhecida pelo Ministério da Saúde, deu a essa profissional autonomia para assumir com exclusividade todo o processo de saúde reprodutiva - pré-natal, parto e pós-parto, assim como a gestão do cuidado e das atividades relacionadas ao funcionamento pleno da unidade de saúde, tornando esse modelo totalmente autônomo em relação à supervisão médica e hospitalar.
} 


\section{REFERÊNCIAS}

CPDCF.

Casa de Parto David Capistrano Filho.

Disponível em: <http://smsdc-casadeparto.

blogspot.com/>. Acesso em: 23 mar. 2018. s.d.

MOURA, Carla F.S. de.

Casa de Parto David Capistrano Filho: a

participação das enfermeiras nas lutas do campo obstétrico. Dissertação (Mestrado em Enfermagem) - Universidade do Estado do Rio de Janeiro, Rio de Janeiro. 2009.
ROMAR, Juliana.

Casa de parto da prefeitura completa dez anos com mais de 2.300 nascimentos. Disponível em: <http://www.rio.rj.gov.br/web/guest/ exibeconteudo?id=4660027>. Acesso em: 23 mar. 2018. 2014. 